\title{
LUMBOSACRAL TRANSITIONAL VARIATION: A SYSTEMATIC REVIEW OF LITERATURE
}

\author{
By \\ Hessain Abo El-Ghait, Mohamed Moawad and Assem Rizk Mahmoud \\ Departments of Orthopedic Surgery, Faculty of Medicine, Al-Azhar University \\ Corresponding author: Assem Rizk Mahmoud, \\ E-mail: assemmahmoud8811@gmail.com
}

\begin{abstract}
Background: Lumbosacral transitional variations (LSTVs) are common within the spine, including sacralization of the lowest lumbar vertebral body and lumbarization of the uppermost sacral segment. Low back pain associated with an LSTV may arise from the level above the transition. LSTVs are common in the general population. LSTVs have been classically described as being best imaged on Ferguson radiographs. Symptoms can originate from the anomalous articulation itself, the contralateral facet joint, instability and early degeneration of the level cephalad to the transitional vertebrae, and nerve root compression from hypertrophy of the transverse process.
\end{abstract}

Objective: To highlight the variations of lumbosacral anatomy.

Materials and methods: We conducted a comperhensive electronic search in Pubmed, MEDLINE and Chocrane library databases, for articles that published between December 2003 and December 2018 using these keywords: lumbar and sacral vertebrae, lumberization, sacralization, low back pain and lumbosacral transitional variation. This review was done using standard methodology outlined in the Cochrane Handbook and reported the findings in accordance with the Preferred Reporting Items for Systematic Reviews and Meta-analyses (PRISMA) statement guidelines.

Results: From electronic searching, a total of 1160 studies were identified. 1060 studies remained after duplicates were omitted. Based on titles and abstracts, 900 studies were removed. Four were removed because they were ongoing studies and two were excluded due to inability to translate or obtain full text. An additional 146 were excluded based on full text records assessed for eligibility.

Conclusion: Our systematic review demonstrated a difference in the dural sac (DS) termination level between groups of transitional vertebra with lumbarizaion and sacralization, which means that the position of the dural sac tip in the lumbarization group was significantly lower than in the sacralization group, and in the lumbarization group, the dural sac tip was located at the S3.

Keywords: Lumbar and sacral vertebrae, Lumbosacral transitional variation.

\section{INTRODUCTION}

Lumbosacral transitional variations (LSTV) are a common congenital anomaly, with reported prevalence of 3.3$35.6 \%$, where either the lowest lumbar vertebra sacralizes, or the uppermost sacral segment lumbarizes. Sacralized L5 exhibit morphologic features ranging from elongated transverse process (es) to complete sacral fusion. Lumbarized S1 may appear more square-like in the sagittal plane, possess full sized S1-S2 intervertebral disk and/or lumbar-type facet joints, and articulate abnormally to the remainder of the sacrum (Tins and Balain, 2016). 
Lee et al. (2015) showed LSTV were associated with increased risk of degenerative change in the disc superior to the transitional vertebrae. Ahn et al. (2017) proved that LSTV limits clinical improvement following lumbar microdiscectomy with regard to pain intensity and recurrence. Additionally, LSTV is associated with nerve root and SI symptoms. Illeez et al. (2018) determined the prevalence of SI dysfunction in LBP patients with transitional vertebrae was significantly higher than LBP patients without.

While LSTVs can be identified on all imaging modalities, they have been classically described as being best imaged on Ferguson radiographs (AP radiographs angled cranially at $30^{\circ}$ ). Currently, given its superior spatial resolution, CT is the best imaging technique for characterization of LSTVs. These anomalies are usually identified incidentally because CT is not typically indicated to identify LSTVs, due to radiation concerns, nor is it the preferred imaging technique used to evaluate patients with nontraumatic low back pain. In these clinical cases, MRI is more often indicated, given its superior tissue differentiation within and around the spine (Quinlan et al., 2010).

Correct identification of an LSTV is essential because there are important clinical implications. Inaccurate identification may lead to surgical and procedural errors and poor correlation with clinical symptoms. Additionally, although the relationship of low back pain and LSTV, termed "Bertolotti Syndrome," has been debated in the literature since its initial description in 1917, many support this association (Quinlan et al., 2010).

The purpose of this study was to highlight the variations of lumbosacral anatomy, clinical manifestations, diagnosis and treatment of lumbosacral transitional variation.

\section{PATIENTS AND METHODS}

We conducted a comperhensive electronic search in Pubmed, MEDLINE and Chocrane library databases, for articles that published between December 2003 and December 2018 using these keywords: lumbar and sacral vertebrae, lumberization, sacralization, low back pain and lumbosacral transitional variation.

\section{Inclusion criteria:}

- Randomized control trial (RCT) studies and prospective and retrospective studies.

- Published in English language from 2000 to December 2015.

- That highlighting procedures including $\mathrm{X}$ rays, $\mathrm{CT}$ and MRI.

- Outcome measures; greater than or equal to one pre-specified quantifiable outcome measures (they included measures of functional and clinical outcomes).

- In vivo studies.

- Level of evidence; papers provide levels of I to IV of evidence.

\section{Exclusion criteria:}

- Retrospective studies, case report studies.

- Non-English papers. 
- Animal or cadaveric studies.

- Articles with no functional and clinical outcome measurement data.

- Skeletal immature patients.

Tools used:

- The Cochrane Risk for Bias Assessment Tool.

- The Newcastle-Ottawa Tool.

- The Emergency Care Research Institute (ECRI) before and after assessment tool.

We made a qualitative assessment by reviewing the direction, magnitude and statistical significance of each of the contributing study findings.

- For primary and secondary outcomes, we used RevMan 5.3 to calculate pooled summary estimates and generate forest plots. For continuous variables of length of stay, operative time and estimated blood loss, we utilized random effect models to calculate weighted mean differences (WMD) and 95\% confidence intervals (CI), we utilized Peto-fixed effect odds ratios and $95 \% \mathrm{CI}$.

- For outcomes regarding percentages of patients discharged to home and percentage of postoperative complications, we used random effect models to calculate relative risk (RR) and $95 \% \mathrm{CI}$.

- For secondary outcomes that could not be pooled quantitatively as gait analysis, post-operative markers of inflammation and muscle damage, and post-operative narcotic consumption, we provided a qualitative summary of the general trends we observed based on the reported findings.

We used CMA to calculate the effect which standard difference in means and then forest plot in Rev man as Rev man cannot calculate the effect of pre and post. 


\section{RESULTS}

From electronic searching, a total of 1160 studies were identified. 1060 studies remained after duplicates were omitted. Based on titles and abstracts, 900 studies were removed. Four were removed because they were ongoing studies and two were excluded due to inability to translate or obtain full text. An additional 146 were excluded based on full text records assessed for eligibility, leaving 8 studies that met all inclusion criteria.

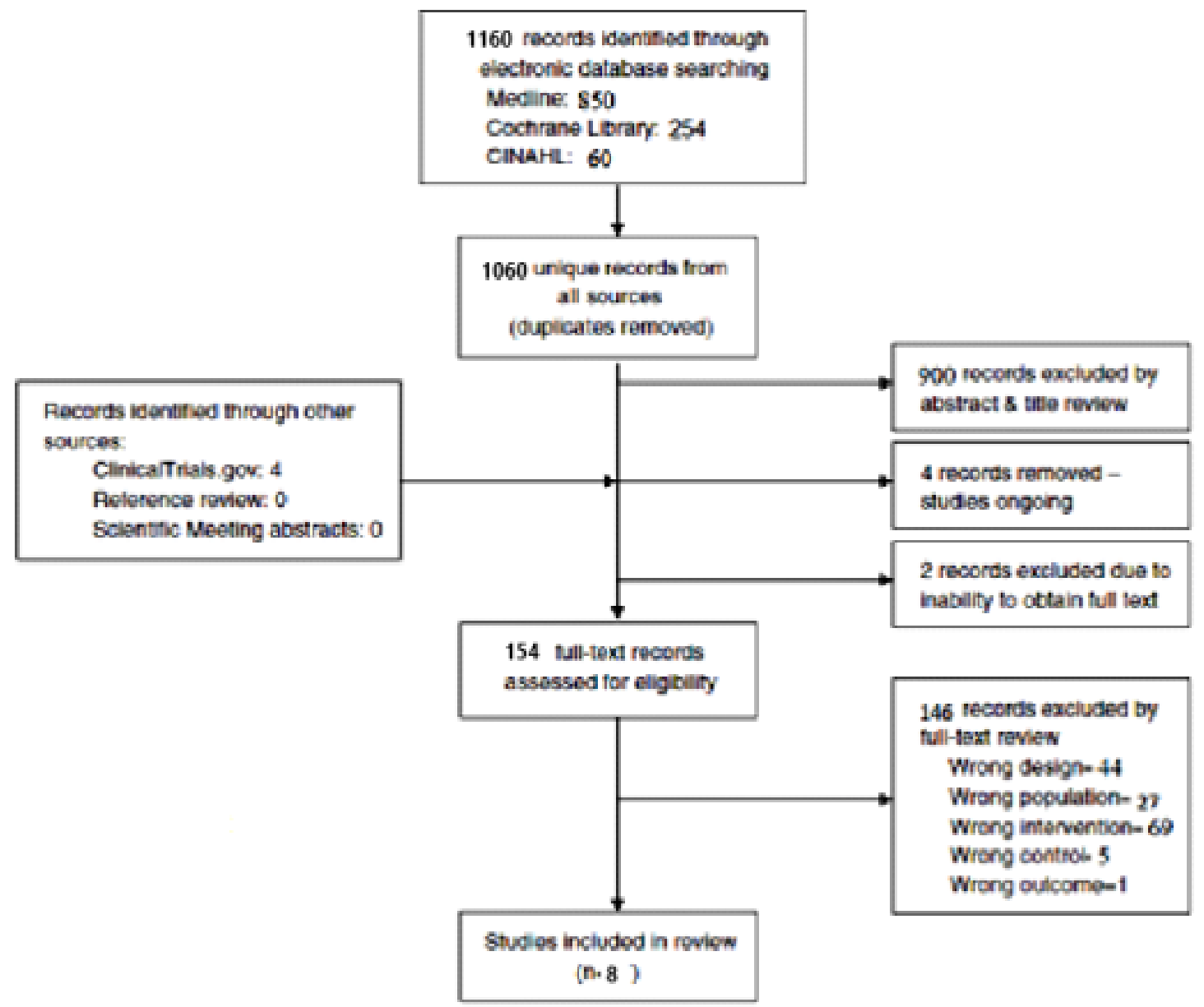

Figure (1): Flow chart 
LUMBOSACRAL TRANSITIONAL VARIATION: A SYSTEMATIC...

Table (1): Type, duration, diagnosis, grades of LSTV of the studies included

\begin{tabular}{|c|c|c|c|c|c|}
\hline & $\begin{array}{l}\text { Diagnostic } \\
\text { method }\end{array}$ & $\begin{array}{l}\text { Type of } \\
\text { study }\end{array}$ & $\begin{array}{c}\text { Number } \\
\text { of } \\
\text { patients }\end{array}$ & Prevalence & Grades \\
\hline $\begin{array}{l}\text { Uçar et al., } \\
2013\end{array}$ & & $\begin{array}{l}\text { Retrospective } \\
\text { (12 months) }\end{array}$ & 500 & $\begin{array}{c}23.6 \% .2 .4 \% \\
\text { had } \\
\text { lumbarization; } \\
\text { sacralization } \\
\text { was in } 21.2 \% \text {. } \\
\text { The incidence } \\
\text { ratio of } \\
\text { sacralization to } \\
\text { lumbarization is } \\
\text { approximately } \\
9.8: 1 .\end{array}$ & $\begin{array}{c}\text { Higher incidences of Type IB and Type IIB } \\
\text { were found in men } \\
\text { Type Ia was the most prevalent type } \\
\text { According to sacralization classification, the } \\
\text { most common } \\
\text { anatomical variant was Castellvi Type IA } \\
\text { (6.8\%), followed by Type IB } \\
(5.4 \%) \text {, Type IIA (1.6\%), Type IIB }(1.8 \%) \text {, } \\
\text { Type IIIA (1.4\%), Type IIIB } \\
(3.4 \%) \text {, and Type IV }(0.8 \%)\end{array}$ \\
\hline $\begin{array}{l}\text { Sekharappa } \\
\text { et al., } 2014\end{array}$ & $\begin{array}{c}\text { Plain } \\
\text { radiography } \\
\text { and MRI }\end{array}$ & Retrospective & & $\begin{array}{l}\text { Overall } \\
\text { prevalence of } \\
13 \% \text {. The } \\
\text { overall } \\
\text { prevalence of } \\
\text { sacralization } \\
\text { was } 11 \% \text { and } \\
\text { lumbarisation } \\
\text { was } 2 \% \text {. } \\
\end{array}$ & $\begin{array}{l}\text { The type IIA pattern was found to be the } \\
\text { commonest followed by type IIIB }\end{array}$ \\
\hline $\begin{array}{l}\text { Lee et al., } \\
2015\end{array}$ & $\begin{array}{c}\text { Plain } \\
\text { radiography } \\
\text { and CT }\end{array}$ & Prospective & 385 & $\begin{array}{l}12.2 \%(47 \\
\text { patients); } 31 \\
\text { cases }(8.1 \%, \\
31 / 385) \text { showed } \\
\text { sacralization } \\
\text { of L5, and the } \\
\text { other } 16 \text { cases } \\
(4.2 \%, 16 / 385) \\
\text { were lumbarized }\end{array}$ & $\begin{array}{c}\text { The proportion of } \\
\text { grade II or more disc degeneration at the L4-5 } \\
\text { level was higher in } \\
\text { the LSTV }(+) \text { group than in the LSTV( }- \text { ) } \\
\text { group }(29.8 \% \text { vs. } 19.2 \%) \\
\text { although it was not statistically significant ( } P \\
=0.093) \text {. } \\
\text { Specifi cally, } 6 \text { type } \\
\text { IIa, } 4 \text { type IIb, } 19 \text { type IIIa, } 15 \text { type IIIb, and } 1 \\
\text { type IV LSTVs. were found using plain } \\
\text { radiographs, and } 13 \text { type IIa, } 8 \text { type } \\
\text { IIb, } 8 \text { type IIIa, } 16 \text { type IIIb, and } 2 \text { type IV } \\
\text { LSTVs were found } \\
\text { by CT. }\end{array}$ \\
\hline $\begin{array}{l}\text { Son et al., } \\
2015\end{array}$ & & $\begin{array}{l}\text { Prospective } \\
\text { (for } 1 \text { year) }\end{array}$ & 291 & $\begin{array}{c}16.2 \% ; 33 \\
\text { sacralization } \\
\text { (70.2\%) and } 14 \\
\text { lumbarization } \\
(29.8 \%)\end{array}$ & $\begin{array}{c}\text { Sacralization of L5 was observed in } 33 \\
\text { patients: } 4 \text { with } \\
\text { type I, } 13 \text { with type II, } 10 \text { with type III, and } 6 \\
\text { with type } \\
\text { IV. The level of disc herniation in group A } \\
\text { was } \\
\text { L3-4 for five patients, L4-5 for } 37 \text { patients, } \\
\text { and L5-S1 } \\
\text { for five patients. }\end{array}$ \\
\hline $\begin{array}{l}\text { Tins and } \\
\text { Balain, } 2016\end{array}$ & MRI & $\begin{array}{l}\text { Retrospective } \\
(28 \text { months })\end{array}$ & 420; & $\begin{array}{c}2.9 \%(66.7 \% \\
\text { sacralization, } \\
33.3 \% \\
\text { lumbarization) }\end{array}$ & \\
\hline $\begin{array}{l}\text { Jagannathan } \\
\text { et al., } 2017\end{array}$ & MRI & & 312 & $\begin{array}{c}18.6 \%(14.7 \% \\
\text { had } \\
\text { sacralization, } \\
\text { and 3.8\% had } \\
\text { lumbarization) }\end{array}$ & $\begin{array}{l}50 \% \text { were on group IIIb, } 37 \% \text { of patients with } \\
\text { sacralization were group IIa }\end{array}$ \\
\hline $\begin{array}{l}\text { Kim et al., } \\
2018\end{array}$ & $\begin{array}{l}\text { Plain } \\
\text { radiology }\end{array}$ & Retrospective & 298 & $\begin{array}{c}14 \% ; \\
\text { lumbarization in } \\
3 \% \text {,sacralization } \\
5.1 \% \\
\end{array}$ & Most common site L5 \\
\hline $\begin{array}{l}\text { Jeon et al., } \\
\quad 2018\end{array}$ & $\begin{array}{l}\text { MRI } \\
\text { radiography }\end{array}$ & Retrospective & 494 & $\begin{array}{c}40.7 \% \\
\text { sacralization, } \\
59.3 \% \\
\text { lumbarization }\end{array}$ & $\begin{array}{c}20.4 \%) \\
\text { had LSTV type I, (39.3\%) type II, }(28.5 \%) \\
\text { had LSTV type III. LSTV type I } \\
\text { [31.4\% in lumbarization vs. } 9[4.5 \%] \text { of } \\
\text { sacralization } P<.001) \text {, whereas LSTV type III } \\
\text { and IV were significantly more common in the } \\
\text { III and IV in } 41.8 \% \text { and } 17.9 \% \text { in sacralization } \\
\text { group while type III and IV in lumbarization } \\
\text { group was in } 19.5 \% \text { and } 7.5 \% \text { respectively }\end{array}$ \\
\hline
\end{tabular}




\section{DISCUSSION}

Ancient human skeletal remains, when found in well-preserved condition, allow inferences about the etiology of pathology and make it possible to estimate health conditions in past communities. Paleopathological evidence for congenital and degenerative disorders of the lumbosacral vertebrae is informative about ancient individual lifeways and physical conditions. Pathological findings of the lumbosacral vertebrae, such as spina bifida occulta (SBO), lumbosacral transitional vertebrae (LSTV), and spondylolysis, have been observed in archaic hominins (Ruhli et al., 2016).

Lumbosacral transitional vertebrae (LSTV) are a relatively common variant and can be seen in 25\% (range 15-35\%) of the general population. Morphologically, LSTV have intermediate characteristics between the sacral and the lumbar vertebrae, and the transitional segment shows an elongation of its transverse process, with varying degrees of fusion. Back and buttock pain can be associated with LSTV, as shown by Nardo et al. (2012). Appreciation of anatomical variations due to LSTV may impact safe performance of caudal epidural steroid injection.

Caudal epidural block (CEB) is a relatively safe procedure which is used in a wide range of clinical settings. It is used for intra and postoperative analgesia in a variety of operations and has become one of the most commonly performed interventions in pain practice for those with low back pain and radiculopathy. Although it is rare, the potential complication of dural puncture during CEB could occur. Therefore, determining the anatomical location of the sacral hiatus, the sacrococcygeal ligament, and the level of termination of the dural sac (DS) are essential before performing CEB, to prevent dural puncture (Kim et al., 2013).

In this context, the questions could arise whether the termination level of the DS of LSTV patients would be significantly different from that of others with similar clinical symptoms and furthermore, within the LSTV group, the caudal level of the DS would be different based on the type of transitional segment; sacralization and lumbarization.

Although there have been many studies regarding the mean level of termination of the DS in patients with low back pain and or sciatica, there is a lack of publication that evaluated the DS termination separately for LSTV patients. Therefore, the purpose of the present study was to highlight the variations of lumbosacral anatomy regarding clinical manifestations, recent diagnosis and treatment. This systematic review included 8 studies.

Our systematic review demonstrated a difference in the DS termination level between groups of transitional vertebra with lumbarizaion and sacralization, which means that the position of the DS tip in the lumbarization group was significantly lower than in the sacralization group, and in the lumbarization group, the DS tip was located at the S3.

Uçar et al. (2013) determined, by plain radiography, if there is a relationship between lumbosacral transitional vertebrae and low back pain and concluded that those lumbosacral transitional segments are common in the 
low back pain population. But no relationship found between age and genders.

Sekharappa et al. (2014) determined the prevalence of LSTV and studied its significance with respect to clinically significant symptoms (low back pain and/or ra-dicular leg pain), radiological disc degeneration and disc herniations. They found that the prevalence of LSTV in urology outpatients, spinal outpatients and discectomy patients was $8 \%, 14 \%$, and $17 \%$ respectively, with an overall prevalence of $13 \%$. Females had about 1.3 times higher prevalence of LSTV as compared to males. Almost 30\% of patients operated on for symptomatic last mobile disc herniation had LSTV. The probability of finding LSTV in patients with clinical symptoms requiring an $\mathrm{X}$ ray, those requiring an MRI and those requiring surgery for last mobile disc herniation was $1.75,2.3$, and 3.6 times higher respectively than those attending a urology OPD with non-spinal symptoms. There was a definite causal relationship between the transitional vertebra and degeneration of the disc immediately cephalad to it.

Lee et al. (2015) determined the prevalence of LSTV with computed tomography (CT) and correlated LSTV presence with lumbar disc degeneration at each level by magnetic resonance imaging (MRI). They concluded that the prevalence of LSTV in patients with AIS was found to be $12.2 \%$. The early disc degeneration at the L4-5 level in the LSTV (+) group could not be statistically confi rmed, although a trend was found. However, a large lumbar curve is a risk factor for disc degeneration at the L5-S1 level. So, if patients with AIS with large lumbar curves have LSTV, consideration should be given to stopping distal fusion at L3 instead of L4.

Son et al. (2015) investigated whether the presence of LSTV affects the clinical outcomes of TFEI for LDH and whether these outcomes are affected by sacralization or lumbarization in LDH patients with LSTV. They concluded that disc herniation commonly occurred in the paracentral area, regardless of whether or not the patient had LSTV. However, the level of disc herniation was differed significantly among the three groups. The proportion of patients with disc herniation at the level of L4-5 was significantly higher in patients with sacralization than in patients with lumbarization or the patients without LSTV. This phenomenon might be associated with stress concentration due to the loss of motion at the L5-S1, as being adjacent disc degeneration after cervical or lumbar fusion surgery.

Tins and Balain (2016) determined the incidence of numerical variants and transitional lumbosacral vertebrae of the spine in consecutive patients in routine MR imaging practice. They concluded that numerical variants of the spine are common, and were almost 2.5 times as frequent as transitional lumbosacral vertebrae in the study population. While MRI of the lumbar spine can usually identify transitional lumbosacral vertebrae (though not as reliably as radiographs), it cannot identify numerical variants of the spine, which is possible only by imaging of the whole spine. In men, the tendency is toward an increased number of mobile 
vertebrae, whereas the number tends to decrease in women.

Jagannathan et al. (2017) assessed the role of vascular and musculoskeletal anatomical structures in counting of vertebrae and identifying LSTV. Vascular landmarks had variable origin with caudal and cranial shifts in lumbarization and sacralization, respectively. ILL emerged from either L5 alone or its adjacent disc in $93.8 \%$ of cases in the normal group, and ILL was observed in last lumbar vertebra (L4) and its adjacent disc in $80 \%$ of cases. Thus, ILL seems to be useful for the identification of the last lumbar vertebra in cases of sacralization Castellvi III $b$ and IV types. CF was observed at D12 in $96.9 \%$ and $91.7 \%$ in the normal and lumbarization groups, respectively; thus, $\mathrm{CF}$ was identified as a reliable marker for D12 identification. Similarly, PM origin was observed from D12 or D12-L1 in $69.3 \%$ and $95.7 \%$ of patients in the normal and sacralization groups, respectively. Hence, CF, PM origin, and ILLs are good identification markers for D12 and L5, though none of them led to $100 \%$ accurate identification.

Kim et al. (2018) presented a comprehensive analysis of lumbosacral defects documented in human skeletal remains from Joseon tombs of the 16-18th centuries in Korea. They suggested that differences in the prevalence of LSTV between Joseon people in Korea and medieval samples from other countries are minor, indicating that genetic causes are unlikely.

Jeon et al. (2018) investigated the level of DS termination in relation to the spine in patients with LSTV, by using magnetic resonance imaging (MRI), and compared this position between the sacralization and lumbarizaion groups. They demonstrated that pre-procedural MRI to check the anatomical structures, including the level of DS termination and caudal margin of perineural cysts, would be of great use for lowering the risk of unexpected dural puncture during the procedure, especially in the lumbarization cases.

Therefore, when planning caudal procedures for pain management in patients with LSTV, especially in the lumbarization cases, pre-procedural MR imaging to check the termination level of the DS, the distance between the upper margin of the SCM and the end of the DS, and the presence of incidental cystic structures would be of great use for lowering the risk of unexpected dural puncture during the procedure.

The advantage of our systematic review was that we adopted on randomized control trial articles to conduct this study in order to get results can be trusted.

\section{CONCLUSION}

Our systematic review demonstrated a difference in the DS termination level between groups of transitional vertebra with lumbarizaion and sacralization, which means that the position of the DS tip in the lumbarization group was significantly lower than in the sacralization group, and in the lumbarization group, the DS tip was located at the S3. More randomized control trials with long-term outcomes are needed to highlight the variations of lumbosacral anatomy. 


\section{REFERENCES}

1. Ahn SS, Qiu G and Zhao Y. (2017): The clinical significance of lumbosacral transitional vertebrae on the surgical outcomes of lumbar discectomy: a retrospective cohort study of young adults. World Neurosurg., 99: 745-750.

2. Illeez OG, Atıcı A, Ulger EB, Kulcu DG, Ozkan FU and Aktas I. (2018): The transitional vertebra and sacroiliac joint dysfunction association. Eur Spine J., 27: 187-193.

3. Jagannathan D, Indiran $\mathbf{V}$ and Hithaya $F$. (2017): Role of anatomical landmarks in identifying normal and transitional vertebra in lumbar spine magnetic resonance imaging. Asian Spine, 11(3): 365-379.

4. Jeon JY, Jeong YM and Lee SW. (2018): The termination level of the dural sac relevant to caudal epidural blocks in lumbosacral transitional vertebrae: A comparison between sacralization and lumbarization groups. Pain Physician, 21: 7381.

5. Kim SG, Yang JY and Kim DW. (2013): Inadvertent dural puncture during caudal approach by the introducer needle for epidural adhesiolysis caused by anatomical variation. Korean J Pain, 26: 203-206.

6. Kim Y, Kim $H$ and Hong JH. (2018): Lumbosacral defects in a 16th-18th-century Joseon Dynasty Skeletal Series from Korea. Hindawi BioMed Research International, 18: 74-77.
7. Lee CS, Ha JK and Kim DG. (2015): The clinical importance of lumbosacral transitional vertebra in patients with adolescent idiopathic scoliosis. Spine, 40(17): E964-E970.

8. Nardo $L$, Alizai $H$ and Virayavanich $W$. (2012): Lumbosacral transitional vertebrae: Association with low back pain. Radiology, 265: 497-503.

9. Quinlan JF, Duke D and Eustace S. (2010): Bertolotti's syndrome: a cause of back pain in young people. J Bone Joint Surg Br., 88: 1183- 86 .

10. Ruhli FJ, Galassi FM and Haeusler $M$. (2016): Palaeopathology: Current challenges and medical impact. Clinical Anatomy, 29(7): 816-822.

11. Sekharappa V, Amritanand $R$ and Krishnan V. (2014): Lumbosacral transition vertebra: prevalence and its significance. Asian Spine Journal, 8(1): 51-8.

12. Son K, Lee $S$ and Lee GW. (2015): The impact of lumbosacral transitional vertebrae on therapeutic outcomes of transforaminal epidural injection in patients with lumbar disc herniation. Pain Practice, 18: 1-6.

13. Tins BJ and Balain B. (2016): Incidence of numerical variants and transitional lumbosacral vertebrae on whole-spine MRI. Insights Imaging, 7: 199-203.

14. Uçar BY, Uçar DE and Bulut M. (2013): Lumbosacral Transitional Vertebrae in Low Back Pain Population. J Spine, 2(1): 125. 


\section{التباين الانتقالي بين الفقر ات القطنبة و العجزية \\ حسين ابوالغيط, محمد معوض, عاصم رزق محمود \\ قسم جراحة العظام, كلية الطب، جامعة الازهر}

\section{E-mail: assemmahmoud8811@gmail.com}

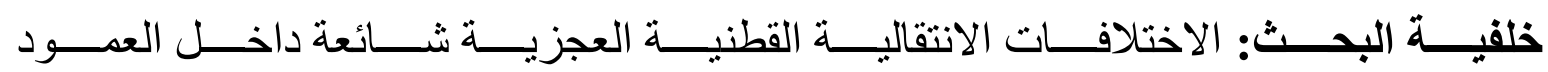

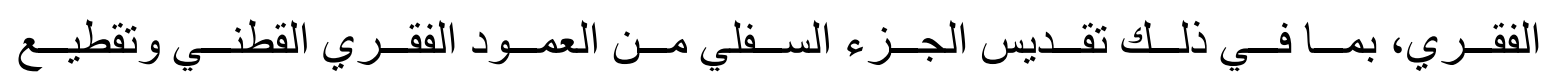

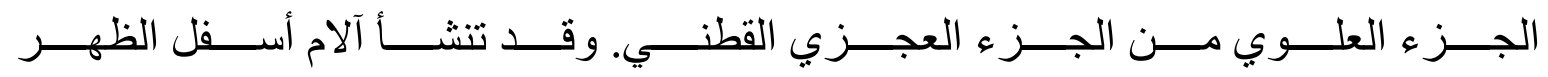

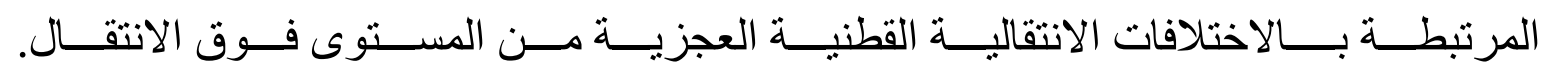

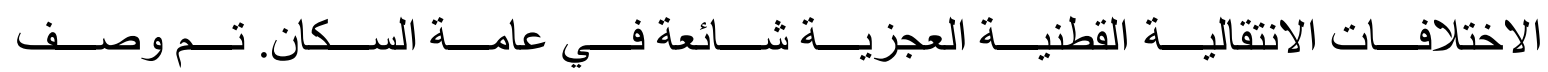

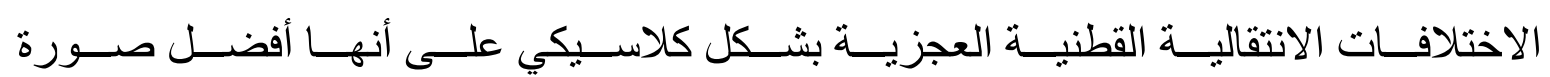

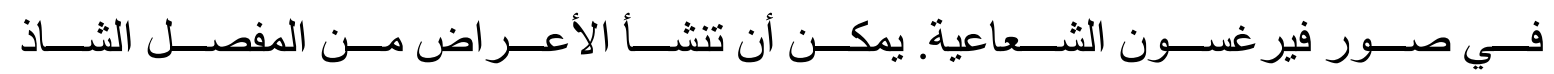

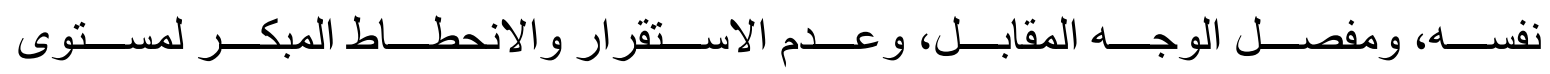

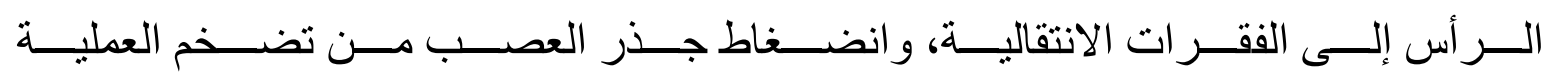

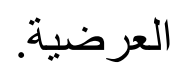

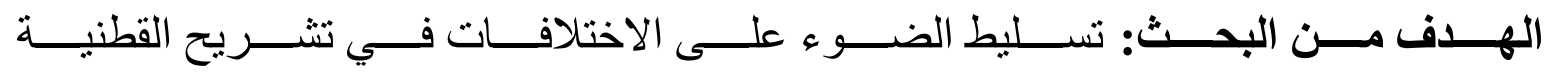
العجزية.

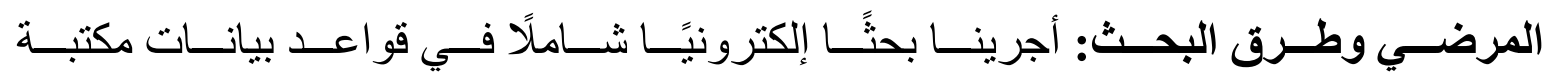
MEDLINE و و Pubmed

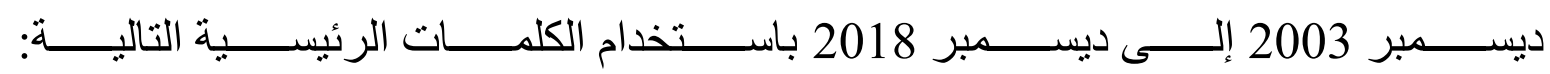

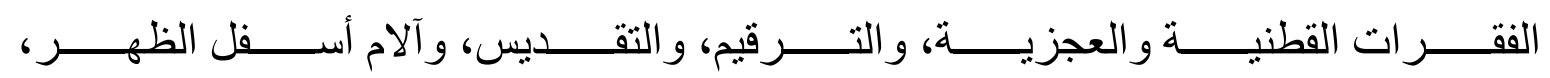

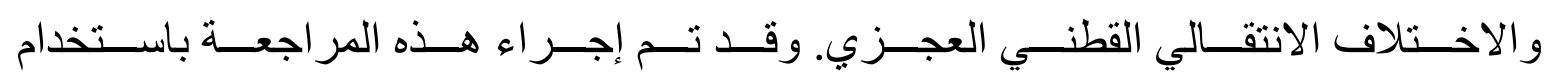

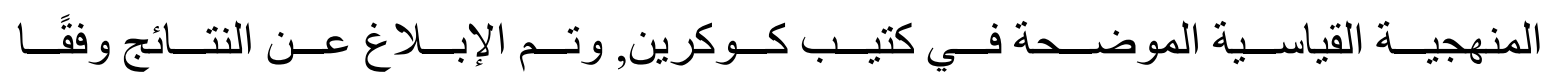

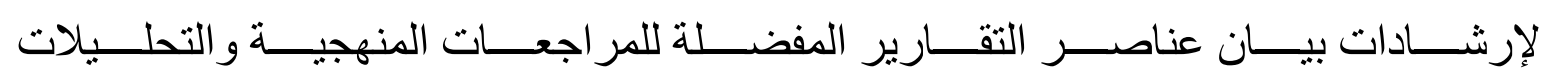




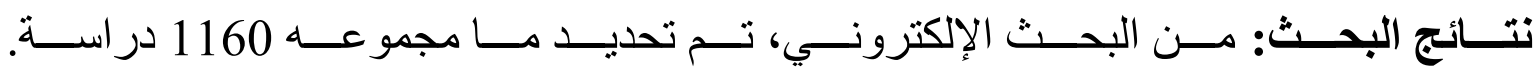

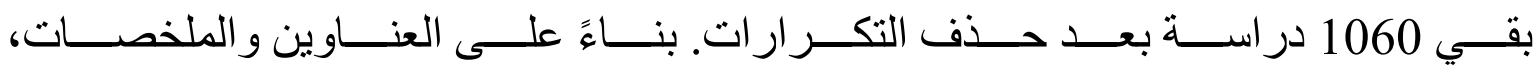

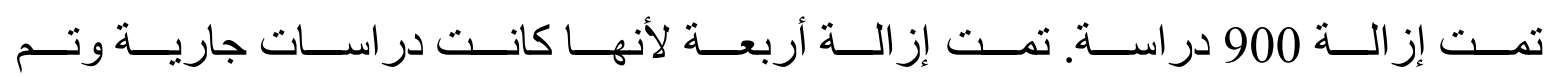

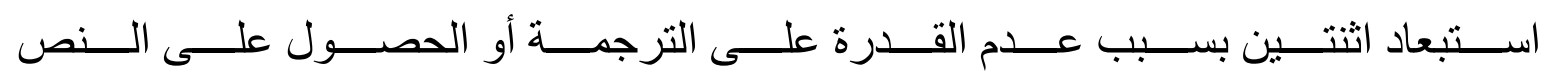

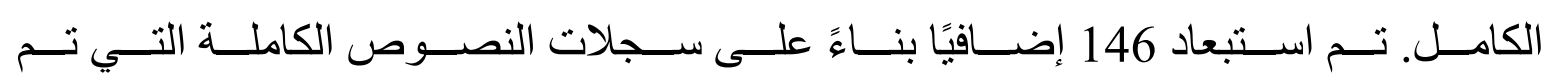
تقييمها من أجل الأهلية.

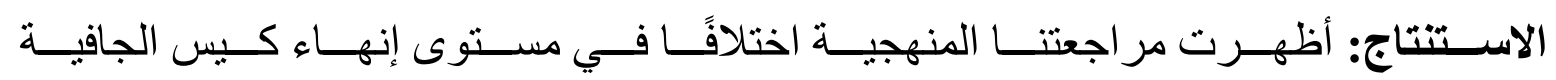

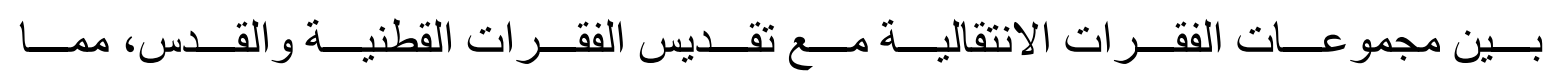

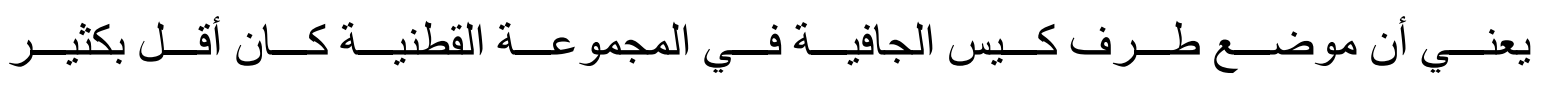

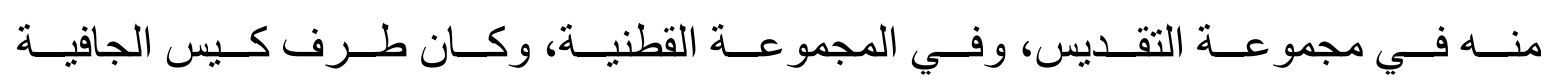

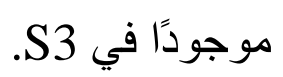

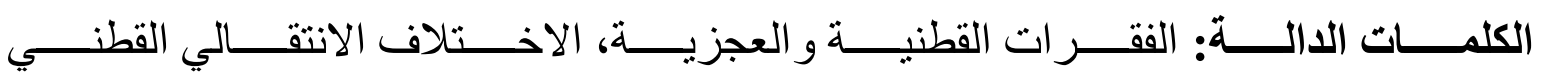
العجزي. 